\title{
Computational Modelling of Liver Metabolism and its Applications in Research and the Clinics
}

\author{
Tanja Cvitanović Tomaš, ${ }^{1, \dagger}$ Miha Moškon, ${ }^{2, \dagger}$ Miha Mraz ${ }^{2}$ \\ and Damjana Rozman ${ }^{1, *}$ \\ ${ }^{1}$ Centre for Functional Genomics and Bio-chips, Institute of Biochemistry, Faculty of Medicine, \\ University of Ljubljana, Slovenia \\ ${ }^{2}$ Faculty of Computer and Information Science, University of Ljubljana, Slovenia \\ ${ }^{\dagger}$ These authors contributed equally to this work. \\ *Corresponding author: E-mail: damjana.rozman@mf.uni-lj.si
}

Received: $15-05-2018$

\begin{abstract}
Computational models of liver metabolism are gaining an increasing importance within the research community. Moreover, their first clinical applications have been reported in recent years in the context of personalised and systems medicine. Herein, we survey selected experimental models together with the computational modelling approaches that are used to describe the metabolic processes of the liver in silico. We also review the recent developments in the large-scale hepatic computational models where we focus on object-oriented models as a part of our research. The object-oriented modelling approach is beneficial in efforts to describe the interactions between the tissues, such as how metabolism of the liver interacts with metabolism of other tissues via blood. Importantly, this modelling approach can account as well for transcriptional and post-translational regulation of metabolic reactions which is a difficult task to achieve. The current and potential clinical applications of large-scale hepatic models are also discussed. We conclude with the future perspectives within the systems and translational medicine research community.
\end{abstract}

Keywords: Hepatic metabolism; systems medicine; modelling and simulation; large-scale metabolic models; NAFLD; liver

\section{Introduction}

Novel high throughput technologies and advanced computation impact the medicine quickly and influentially. Despite this, we still face a number of multifactorial diseases where the diagnosis and treatment remain a hurdle. This is the case as well for the multifactorial liver pathologies where the combinations of poorly defined genetic factors, together with environmental factors, interplay with each other and result in distinct disease phenotypes.

Non-alcoholic fatty liver disease (NAFLD) is the most prevalent form of chronic liver disease in the world. It affects $25 \%$ of the global adult population and as many as $1 / 3$ of people in the developed world. ${ }^{1}$ The disease is manifested by a spectrum of liver pathologies ranging from simple steatosis (fatty liver) to liver cell injury with fibrosis and can end in cirrhosis or liver cancer (hepatocellular carcinoma, HCC). The rising incidence of NAFLD has led to dramatic rise of liver cancer, a disease with poor outcomes and limited therapeutic options. Without treatment, HCC is fatal, with a 5-year survival of only five percent.

Due to individuality of humans and the combinatorial effects, it is virtually impossible to predict all combinations that can lead to a liver disease phenotype. It appears that in each individual a different combination of genetic and environmental factors might be responsible for the multifactorial disease appearance and progression. In addition, such multifactorial conditions combine during the aging. This limits the ability to predict the individuals' disease progression and to discover and/or apply efficient individualized treatments.

We are thus faced with a challenging situation where on one hand there is a large progress in understanding the 
molecular players of the liver disease stages and the overlap with other diseases while the inconsistencies from different studies and different populations leave the impression that we are close to the starting point. A major challenge of today's medicine is thus to incorporate the technological revolution accompanied with expansion of various data into the everyday clinical practice. One example is the knowledge regarding the genetic bases of liver diseases. Despite multiple studies and numerous potentially involved genes, the polymorphisms of a single gene PNPLA3 named also adiponutrin, correlate with the non-alcoholic fatty liver disease progression to later disease stages, including the hepatocellular carcinoma (reviewed in $\left.{ }^{2,3}\right)$.

At present we do not understand the mechanisms and pathways that define a particular liver disease stage, we cannot predict the fate of disease progression nor can we treat NAFLD. To solve such complex questions we must apply innovative systems solutions that in addition to experimentation include also modelling and validation in clinical samples. These will be described in more details in the following chapters of the paper.

\section{Selected Liver Disease Models that Produce Data for Computation}

Cholesterol presents one of the most important metabolites synthesized within liver. Starting point of cholesterol biosynthesis is an acetyl-CoA molecule. The pathway consists of more than 20 enzyme catalysed reactions. ${ }^{4}$ Unlike the pre-squalene part of the cholesterol biosynthesis the exact order of reactions in the post-squalene part has not yet been clarified. Enzyme lanosterol 14a-demethylase i.e. CYP51, the evolutionary most conserved member of the cytochrome P450 family, catalyses the conversion of lanosterol to FF-MAS in the post-squalene part of cholesterol biosynthesis. ${ }^{5}$ Cyp51 is regulated by transcription factor SREBP, via cyclic adenosine monophosphate (cAMP) $)^{6}$ and by the circadian regulation. ${ }^{7}$ Liver disease mouse model in which CYP51 was blocked as the rate limiting enzyme of the post-lanosterol part of cholesterol biosynthesis, exposed the progression of NAFLD in mice, and resulted in a phenotype similar to the metabolic progression of NAFLD towards HCC in humans. ${ }^{8}$ It is impossible to monitor the long-term metabolic progression of NAFLD in human individuals since repetitive liver biopsies are strictly avoided in practice. The complete removal of both Cyp51 gene alleles in mice causes death of the embryo in the 15th day of development, which indicates the importance of cholesterol in embryogenesis. ${ }^{9}$ Cholesterol synthesis mutations may cause severe defects such as Antley-Bixler syndrome, Smith-Lemli-Opitz syndrome and several other genetic diseases. ${ }^{10}$

There are still no approved therapies for NAFLD, which is becoming a major health concern due to increas- ing incidence of obesity in Europe. The problem of NAFLD is its multifactorial nature, with a largely uncharacterized genetic basis and only a few known associated genes. ${ }^{11}$ For several patients, NAFLD presents an initial step of a serious condition called non-alcoholic steatohepatitis (NASH), which includes fibrosis and is the fastest growing cause of HCC. ${ }^{3}$ While HCC prevails in males and is increased in postmenopausal females, the sex-based metabolic cues have not been investigated. ${ }^{12}$ Clinical research and more individualized disease progression monitoring is thus hampered by a lack of reliable non-invasive biomarkers. It currently seems impossible to predict all genetic and environmental factors and their combinations that leads to NAFLD phenotypes. To bridge this gap it is timely to apply a multidisciplinary systems medicine approach to combine experimentation and clinical work with the stateof-the-art multiscale and spatio-temporal liver models. ${ }^{13}$ Only in this way we will be able to fully understand NAFLD as a multifactorial condition and deduce metabolic causes and risk factors in females and males. This article will survey the combination of experimental, clinical, bioinformatics and modelling approaches that present the state-of-the art in identifying potential targets of complex multifactorial NAFLD and other complex liver diseases.

\section{From Dynamical Models of Biochemical Reactions to Virtual Organisms}

Computational modelling approaches that are currently used in the systems biology and systems medicine research communities can be differentiated into two main groups. First are the bioinformatic approaches, which allow us to analyse the experimental data, perform statistical analyses and conduct statistical modelling. The second are computational biology also known as mechanistic or $d y$ namical modelling approaches, which allow us to perform dynamical modelling and execute computational simulations of the systems under the study. ${ }^{14}$ Even though bioinformatic approaches serve to be complementary to the dynamical modelling approaches, the focus of this paper will be made solely on the later.

Dynamical modelling approaches differ in dependence on the data that are available either from experimentalists or already in published literature. They differ as well based on the type and scale of the system we are investigating and also on the level of details we are aiming to describe in silico ${ }^{15}$ (see Table 1 and Figure 1).

Isolated segments of gene regulatory, signalling or metabolic networks are usually described with ordinary differential equations (ODEs). ODEs are composed of the classical Michaelis-Menten equations for modelling the enzymatic reactions. They contain as well Hill equations for modelling the gene regulation and expression, and also 
Table 1: Dynamical modelling approaches depend on the focus, the data and the size of the observed (sub)system. Abbreviations: NF-kB - nuclear factor kappa beta, ODEs - ordinary differential equations, PDEs - partial differential equations, SSA - stochastic simulation algorithm, GEMs genome scale metabolic models, WCM - whole-cell model, M. genitalium - Mycoplasma genitalium, 3D - three dimensional, ABM - agent-based model, OOM - object-oriented modelling.

\begin{tabular}{|c|c|c|c|c|c|}
\hline Focus & Parameters & Multi-scale & Size & $\begin{array}{l}\text { Examples } \\
\text { (applications) }\end{array}$ & $\begin{array}{l}\text { Examples } \\
\text { (approaches) }\end{array}$ \\
\hline $\begin{array}{l}\text { molecular modelling, } \\
\text { isolated segments, only } \\
\text { vital reactions }\end{array}$ & needed & No & small & $\begin{array}{l}\text { oscillatory network } \\
\text { of transcription factor } \\
\text { NF-kB }{ }^{16}\end{array}$ & ODEs, PDEs, SSA \\
\hline $\begin{array}{l}\text { subcellular processes / } \\
\text { reaction networks }\end{array}$ & not needed & no & large & $\begin{array}{l}\text { Comprehensive model } \\
\text { of human metabolism }{ }^{17}\end{array}$ & $\begin{array}{l}\text { Boolean networks, } \\
\text { GEMs }\end{array}$ \\
\hline $\begin{array}{l}\text { integration of subcellular } \\
\text { processes, whole-cells }\end{array}$ & needed & yes & large & $\begin{array}{l}\text { WCM of } M \text {. } \\
\text { genitalium }^{18}\end{array}$ & $\begin{array}{l}\text { integrated models, } \\
\text { WCMs }\end{array}$ \\
\hline $\begin{array}{l}\text { tissues, organs, cell } \\
\text { populations }\end{array}$ & needed & yes & $\begin{array}{l}\text { from small } \\
\text { to large }\end{array}$ & $\begin{array}{l}3 \mathrm{D} \text { liver tissue } \\
\text { models }{ }^{19}\end{array}$ & $\begin{array}{l}\text { ABM, coupled } \\
\text { ODEs and/or PDEs }\end{array}$ \\
\hline all of the above & partially needed & yes & large & LiverSex model ${ }^{20}$ & OOM \\
\hline
\end{tabular}

Human body

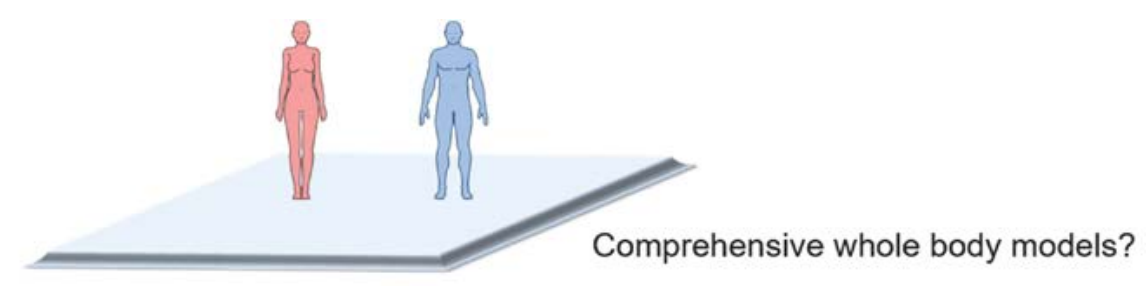

Organs and tissues

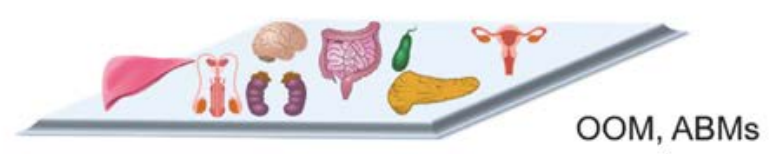

Cells, integrated networks
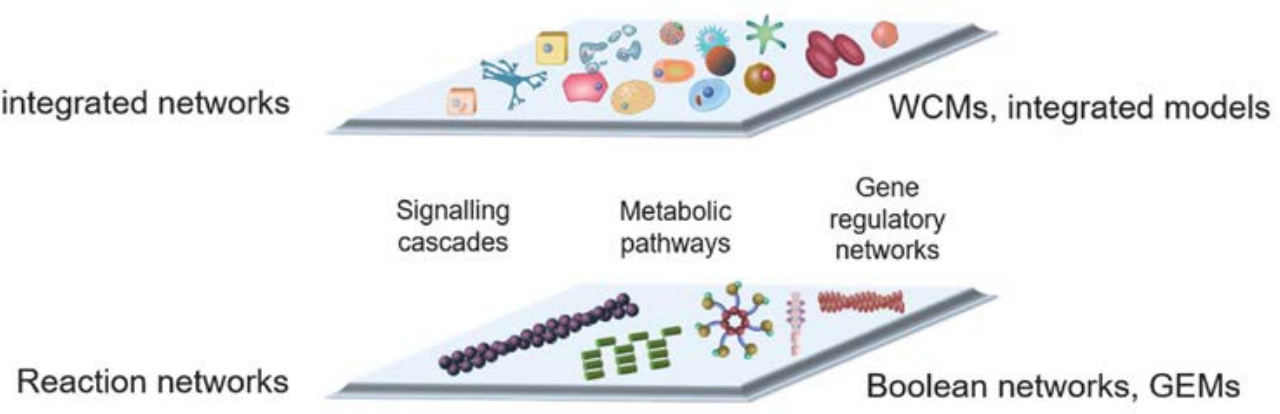

Isolated reactions

ODEs, PDEs, SSA

Figure 1: The focus of computational models scales from simple models describing selected chemical reactions to complex models describing reaction networks and finally organs and tissues. Abbreviations: ODEs - ordinary differential equations, PDEs - partial differential equations, SSA stochastic simulation algorithm, GEMs - genome scale metabolic models, WCMs - whole-cell models, ABMs - agent-based models, OOM - object-oriented model 
first order differential equations for modelling the protein degradation and similar processes. ${ }^{21}$ Models based on ODEs usually present the basis for the so called deterministic modelling, which describes the average of the system's response. Deterministic modelling also presumes a homogeneous distribution of the observed entities through the constant volume of the observed molecular space. ${ }^{22}$ An entity can be anything, from small molecules to proteins and genes. When concentrations of the observed chemical species become small, the noise influences become too large to be simply omitted from the models. ${ }^{23,24}$ In such cases a single-molecule level which is named also the stochastic modelling approach, need to be applied..$^{23,25,26}$ The stochastic modelling bases on the Stochastic Simulation Algorithm (SSA ${ }^{27}$ and on its variations (e.g., $\mathrm{see}^{28}$ ). It can account for the stochasticity of the observed biochemical reactions on the account of a larger computational complexity.

Stochastic as well as deterministic modelling approaches described above require the estimation of biologically relevant parameter values. Parameters are values (numbers) that are mostly based on the rate constants $k$ for the observed biochemical reactions. It is the fact that these models (stochastic and deterministic) are useful only with realistic parameter values. ${ }^{29}$ This means that the simulations that would produce biologically relevant results cannot be performed without the evaluation of kinetic parameter values. Specific parameter values, such as protein binding affinities or their degradation rates, can be experimentally measured. However, several pitfalls exist here. For example, (1) mathematical models usually describe complex processes in a simplified manner, which do not necessarily correspond to the measured biochemical constants (for example, multiple reactions can be lumped into a single virtual reaction) (2) reaction rates may strongly depend on environmental conditions (for example, reaction rates increase at higher temperatures) (3) variations of evaluated parameters may be extremely large (for example, reaction rates may differ significantly within the colony of genetically identical cells) and finally (4) not all parameters can be evaluated neither in vivo nor in vitro. ${ }^{29}$ It can thus happen that the majority of the parameter values that are needed in the model, have to be deduced or inferred. Deduction of the missing parameter values is possible with the so called parameter estimation techniques. These techniques compare the available experimental results with the simulation results from the model, and upon that globally minimize the error function ${ }^{30,31}$. Different parameter estimation techniques that aim to integrate the experimental results within the computational models have already been described (see e.g. ${ }^{32-34}$ ). Even though specific techniques that might be able to cope with the large-scale models have also been proposed recently (see e.g. ${ }^{35}$ ), they are in general still far from being scalable. ${ }^{29}$ Moreover, comprehensive in vivo measurements in animals are still not available even for the most studied organisms. ${ }^{29}$ We must underline at this point that there are few in vivo studies in humans that are ethically feasible. It is, for example, impossible to count on kinetic data from human organs in vivo. Even ex vivo studies relying on data from human liver, are frequently small and difficult to compare with one another. ${ }^{36}$ Consequently, majority of experiments that require e.g. a time-series of data, or data from the inner body organs, rely on experiments on laboratory animals, in line with ethical considerations for work on laboratory animals, including the $3 \mathrm{R}$ (reduce, replace, refine) principles.

Computational approaches that are able to deal with large-scale models have thus evolved into different forms that allow us to fully or partially omit the parameter estimation problem. These approaches are mainly focused to specific segments of observed biological system. For example, gene regulatory or signalling networks can be described with Boolean networks (see e.g. ${ }^{37}$ ), while metabolic networks use the stoichiometric description in the form of genome-scale metabolic models. ${ }^{38}$

Boolean networks (known also as logic models) depict the biological systems as a network of Boolean functions, i.e. functions describing binary relations between inputs and outputs. ${ }^{39,40}$ These networks presume that the observed chemical species can take only two possible values, i.e. absent (0) or present (1). Boolean networks are thus only a rough and approximate description of the system under study, but circumvent several problems of the approaches mentioned before. Boolean models can be established without any knowledge of kinetic parameter values and, when experimental data describing the system's response in different conditions are available, also without the knowledge of exact mechanistic description of the system under study. Their structure can be in many cases inferred solely from the characterization of the system's dynamical response (see e.g. ${ }^{41,42}$ ).

Genome-scale metabolic models (GEMs) describe the in silico relations between the organism's genome and its metabolic phenotype. ${ }^{38}$ In these models, the organism's genome and its annotations are applied to the reconstruction of stoichiometric description of the metabolism. ${ }^{43}$ GEMs have already been established for simple prokaryotic organisms (see e.g. ${ }^{44}$ ) as well as for humans ${ }^{17}$ and other eukaryotes (see e.g. ${ }^{45}$ and $^{46}$ ). These models represent the general metabolism encoded within the genome of the organism under study and can be further refined to reflect experimental data observed in different environmental conditions, in different cell strains (see e.g. ${ }^{46}$ ), in different tissues (see e.g. ${ }^{47}$ ), organs (see e.g. ${ }^{48}$ ), diseases (see e.g. ${ }^{49}$ ), as well as within specific individuals (see e.g. ${ }^{50}$ ), using dedicated computational algorithms, such as GIMME ${ }^{51}$, mCADRE ${ }^{47}$ and CORDA $^{52}$. GEMs can be used to assess the metabolic fluxes that bring the observed metabolic network into an optimal steady-state under given criteria and optimisation function, such as maximal biomass production. Flux-balance analysis $(\mathrm{FBA})^{53}$ and other constraint-based approaches under the hood of COBRA 
methodologies ${ }^{54}$ can be applied for this purpose. These methodologies require the definition of optimisation criteria as well as upper and lower limits of metabolic fluxes, i.e. constraints, through observed reactions, and do not rely on the evaluation of exact values of kinetic parameters. They are, however, limited solely to the observation of the metabolic phenotype within the steady state of the system and without direct interactions with other cellular processes, such as gene regulation and protein-protein interactions.

The integration of GEMs with other cellular networks into integrated models have also been reported in recent years (see e.g. ${ }^{55}$ and $^{56}$ ). The most comprehensive version of these model are so called whole-cell models (WCMs), which integrate the GEMs with the large-scale models of gene regulatory networks, signalling networks, protein-protein networks and other cellular processes. ${ }^{57}$ WCM has already been established for Mycoplasma genitalium. ${ }^{18}$ This model integrates 28 different submodels into a unified WCM that is able to describe the cellular dynamics in the time-span of one cellular division. ${ }^{18}$ Even though this model seems extremely promising, the methodology used in its establishment is hardly scalable. ${ }^{29}$ There are several challenges and problems that currently obstruct the application of WCMs to more complex organisms. ${ }^{58}$ One of the main problems these models are facing is again the evaluation of realistic parameter values, their distributions and uncertainties in order to describe the dynamics of observed systems accurately. ${ }^{29}$ Moreover, the integration of models of different cellular processes as well WCMs with their environment into comprehensive models that bridge the gaps between multiple scales still needs to be addressed sufficiently. ${ }^{58}$

While WCMs try to give an accurate description of all cellular processes, models that are currently being applied to the analysis of intra- or inter-cellular dynamics mostly base on the descriptions of the selected processes that seem to be vital for the analysed aspects of cellular dynamics. These models are usually based on the simplifications that combine and reduce the number of observed biochemical reactions thus reducing also the number of parameters that need to be evaluated. ${ }^{59}$ Since the number of observed biochemical entities is drastically reduced, the ODE- or SSA-based approaches can be applied again.

These models can be integrated into multicellular models describing bacterial populations, tissues or organs with the coupling of differential equations and accounting for spatial as well as temporal dynamics of the system's response (see e.g. ${ }^{60},{ }^{61}$ and ${ }^{62}$ ). An alternative approach that accounts for the spatial aspects of the systems under study is so called agent-based modelling (ABM). ABM describes the dynamics of different individual agents, i.e. in our case cells, that follow predefined rules (describing e.g. cellular motility, growth and basic cellular processes) and communicate using cellular communication mechanisms. ${ }^{15}$ Different easy-to-use computational tools that allow straightforward ABM modelling have been proposed recently (see ${ }^{63}$ for a recent review of these tools and frameworks). These allow computational modelling of bacterial populations (see e.g. ${ }^{64}$ ) as well as computational modelling of tissues and organs (see e.g. ${ }^{65},{ }^{66}$ and ${ }^{67}$ ). The main problem of these approaches is again in their inability to scale up, in the context of increasing the modelling accuracy as well as observed population size ${ }^{63}$. Moreover, large computational complexity of these models usually needs to be addressed with an expensive computer hardware. ${ }^{63,68}$

An alternative to the approaches described above is object-oriented modelling that is based on the systems biology (SysBio) library that was built at the University of Ljubljana. ${ }^{69}$ SysBio library was initially used to construct the first integrated human metabolic model SteatoNet with multi-layered regulation. ${ }^{70}$ This model describes the interaction between multiple tissues and accounts for metabolic reactions as well as for transcriptional and post-transcriptional regulation. ${ }^{70}$ Most of the parameters that describe the dynamics of the observed system can be omitted from the model representation due to the observation of the normalised steady-state of the system's response. Object-oriented modelling approach that is applied here allows us to construct complex models by connecting the objects corresponding to basic biological entities in a meaningful and straightforward way. ${ }^{70}$ Since the number of parameters that need to be incorporated into the model is small, this prevents several problems, such as parameter estimation problems as well as the problem of model overfitting. On the other hand parameters that are used at the end allow us to easily adapt the models to specific data, such as personalised or gender specific data as described in $^{20}$.

\section{Large-scale Computational Models of Liver Metabolism}

Changes in health, which may lead to the development and progression of different diseases, are caused by abnormal modifications of metabolism. Identification and characterization of these modifications have potentials for various applications, which include drug discovery and identification of new biomarkers. ${ }^{71}$ The majority of metabolic disorders occurs in the liver. ${ }^{72,73}$ The study of liver disorders improves the understanding of their physiologi$\mathrm{cal}$ and pathological consequences. Computational models present an indispensable tool for the prediction of the effects of metabolic, genetic or chemical perturbations in liver metabolism and consequently in liver-related disease development and progression. ${ }^{13}$ Traditional methods fail to conduct the analyses in the same scope as in silico methods or can be conducted only under unfeasible costs. They need to be, however, complemented with the computational approaches. ${ }^{15}$ Finally, combination of experimental work, clinical work and computational modelling can be used for understanding the disease mechanisms, for eval- 
uating the clinical efficacy and cost-effectiveness of existing diagnostic methods, for the development of new diagnostic methods and for the proposal of new drugs $^{73}$ (see Figure 2).

The liver is a key organ maintaining the metabolic homeostasis in the human body via synthesis, storage, and degradation of metabolites. ${ }^{76}$ The use of computational models in liver research has been increasingly growing in

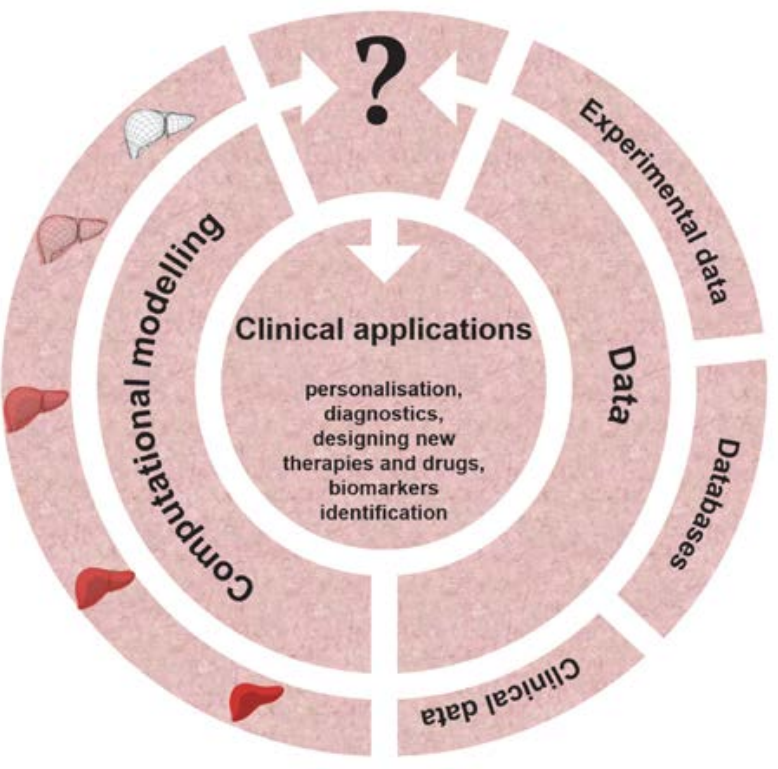

Figure 2: Computational models are complemented with experimental, literature and clinical data, which allows their transition towards clinical applications. recent years (see Table 2 ). Most computational liver models are focused to the isolated liver (hepatic) metabolic mechanisms. For example, a detailed kinetic model of glycolysis, gluconeogenesis, and glycogen metabolism in human hepatocytes under the hormonal control of insulin, glucagon, and epinephrine, presents a tool for understanding the role of the liver in glucose homeostasis under normal conditions, in patients with diabetes or with glycogen storage diseases. ${ }^{77}$ Different models are used to analyse different specific aspects of liver metabolism, such as energy metabolism ${ }^{78}$, fat accumulation ${ }^{79}$, iron metabolism ${ }^{80}$ and xenobiotic metabolism ${ }^{81}$. Even though liver exhibits a large dynamical complexity, their microscopic architecture is remarkably uniform. The uniformity of the liver structure makes the modelling of the hepatic architecture relatively easy, which is indicated by several in silico models of hepatic structural architecture. ${ }^{82,83}$ These models help us to explain how cells form functional tissues, as for example in the 3-dimensional computational model of liver regeneration..$^{84}$

To date, only selected computational approaches of hepatic metabolism have been shifted to clinical application. ${ }^{43}$ Individualized options for medical care of patients with HCC are not available yet, but there are large efforts to develop personalized systems care for them. ${ }^{85} \mathrm{HCC}$ presents a global health problem because it is the seventh most common cancer in the world and the third leading cause of cancer-related deaths. ${ }^{86}$ Research in personalized approaches in hepatology has delivered different examples of successful application of systems biology such as HCC GEMs, which improved the HCC stratification and sug-

Table 2: State-of-the-art computational models used in the liver research. Only major large-scale computational models are included within the table. Abbreviations: GEM - genome scale metabolic models, HCC - hepatocellular carcinoma, NAFLD - non-alcoholic fatty liver disease, NASH non-alcoholic steatohepatitis, SteatoNet - steatosis network.

\begin{tabular}{|c|c|c|c|}
\hline & Type & Description and applications & Reference \\
\hline HepatoNet1 & GEM & $\begin{array}{l}\text { first hepatic GEM; explained the relations between the available oxygen levels and } \\
\text { the nutrients availability in the hepatic detoxification of ammonia }\end{array}$ & 74 \\
\hline iHepatocyte 2322 & GEM & $\begin{array}{l}\text { composed of the hepatocyte, the uptake and secretion of VLDL, LDL and HDL } \\
\text { lipoproteins, and the formation and/or degradation of lipid droplets; used to simulate } \\
\text { the progression of NAFLD to NASH; identified the potential therapeutic targets for } \\
\text { treatment of NASH }\end{array}$ & 48 \\
\hline HCC GEM & GEM & $\begin{array}{l}\text { personalised iHepatocyte } 2322 \text { model to HCC patients; identified } 101 \text { antimetabolites } \\
\text { with tumour suppression effect in the HCC; identified l-carnitine as suppressor of HCC } \\
\text { progression by inhibiting } \beta \text {-oxidation }\end{array}$ & 50 \\
\hline iHCC2578 & GEM & $\begin{array}{l}\text { reconstructed from the proteome and transcriptome of } 361 \text { HCC tumors and } 49 \\
\text { noncancerous liver samples; used to study acetate utilization and HCC; identified } \\
\text { deregulation of fatty acid oxidation as a vital process for cell proliferation in HCC }\end{array}$ & 75 \\
\hline SteatoNet & OOM & $\begin{array}{l}\text { integrated human metabolic model with multi-layered regulation; used to explain } \\
\text { the relations between the liver and other organs in the development of NAFLD; identified } \\
\text { ketone body metabolism, cholesterol transport and regulatory functions of FXR, LXR and } \\
\text { SREBP2 as crucial steps in NAFLD development and progressions }\end{array}$ & t \\
\hline LiverSex & OOM & $\begin{array}{l}\text { adaptation of SteatoNet to gender-specific models; used to investigate gender-dependent } \\
\text { complex liver pathologies; identified the partition of fatty acids into different pathways as } \\
\text { a possible NAFLD protective mechanisms in females; identified PGC1A, PPARa, FXR and } \\
\text { LXR as regulatory factors for gender dependent personalized treatment of NAFLD }\end{array}$ & d \\
\hline
\end{tabular}


gested new targets for personalized treatments. ${ }^{50,75,87}$ Different GEMs have been focused on the human liver metabolism. HepatoNet $1^{74}$ is a product of the liver adaptation of the human metabolic network Recon $1^{88}$ using the extensive knowledge and databases for hepatocyte representation. HepatoNet1 has been used to explain the relations between the available oxygen levels and the nutrients availability in the hepatic detoxification of ammonia. HepatoNet1 presents a starting point for the reconstruction of other hepatocyte-specific GEMSs, for example iLJ1046 $6^{89}$, iAB676 $6^{90}$, iHepatocyte $1154^{91}$ and iHepatocyte $2322^{48}$. iHepatocyte 2322 currently presents the most powerful liver-related GEM. It was established with the combination of various clinical, biochemical and genetic studies. Its main aim was to provide the identification of novel biomarkers and therapeutic targets for NAFLD. Simulation of NAFLD progression to NASH has exposed serine deficiency as the main cause in NASH patients. iHepatocyte 2322 was used to show that increasing serine level in hepatocytes as a consequence of the serine uptake as a dietary supplement could prevent NASH progression. Phosphoserine phosphatase and hydroxymethyltransferases 1 as well as branched chain amino-acid transaminase 1 were identified as potential therapeutic targets for the treatment of NASH. ${ }^{48}$

SteatoNet ${ }^{70}$ presents an OOM model, which was established to increase the understanding of the relations between the liver and other organs in the development of NAFLD. SteatoNet was used to identify the interactions between liver and adipose tissue as critical for the pathogenesis of NAFLD. Ketone body metabolism, cholesterol transport, and regulatory functions of farnesoid $\mathrm{X}$ receptor, liver $\mathrm{X}$ receptor and sterol regulatory element-binding protein 2 were recognized as novel crucial steps of NAFLD development and progressions. However, the liver is well known as one of the most sexually dimorphic non-reproductive organs ${ }^{92}$, which is also indicated by sex differences in liver-related disease prevalence and progression. ${ }^{93} \mathrm{He}-$ patic large-scale metabolic models are, on the other hand, uniform models and do not differentiate between genders. They are constructed and validated mostly on male data, also because of the lack of liver transcriptome-based studies that would take into account both genders. ${ }^{94}$ With the goal to investigate differences in NAFLD progression be-

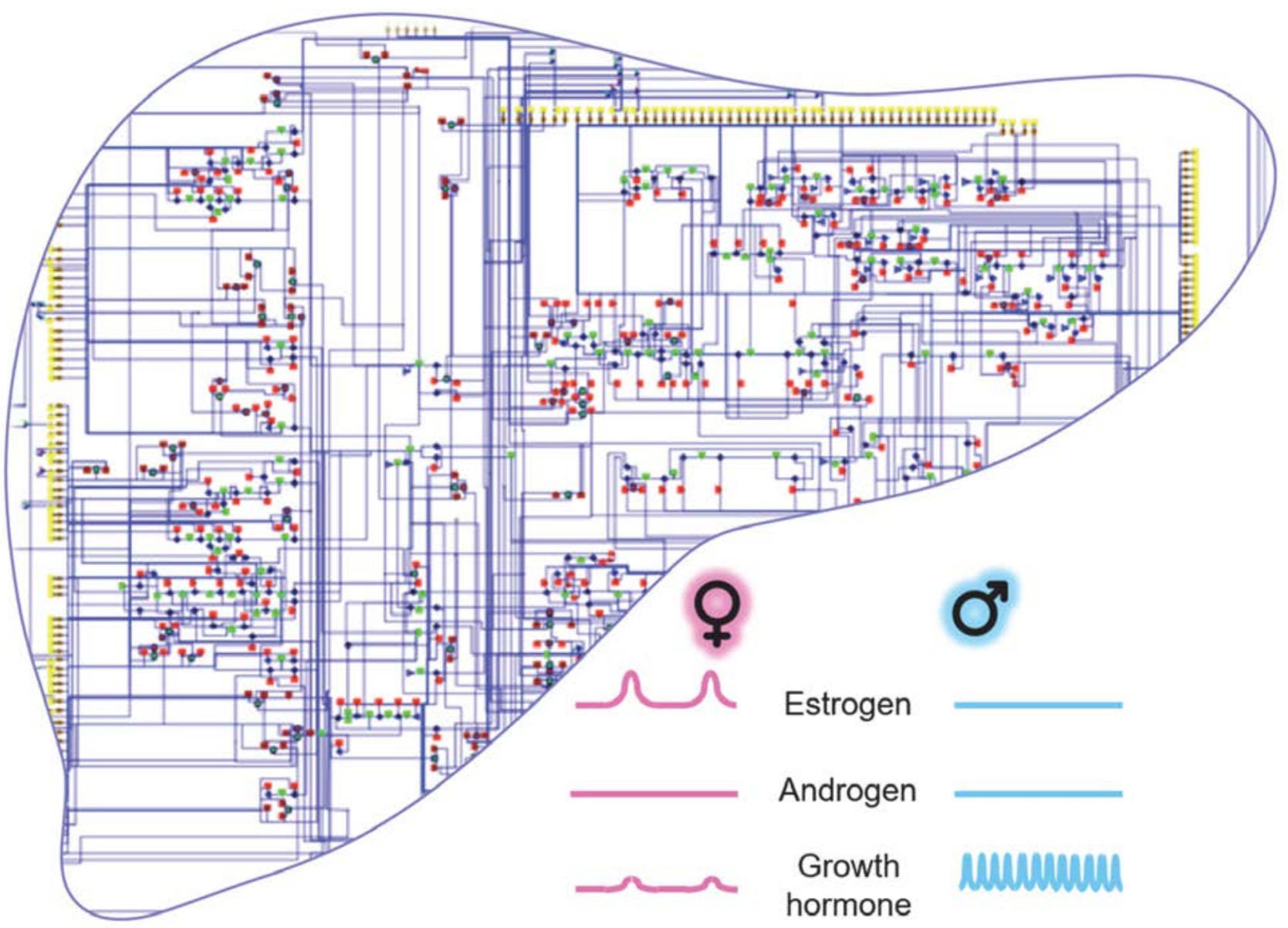

Figure 3: LiverSex presents the gender-based adaptation of the SteatoNet model, and is able to provide detailed insights into gender-dependent complex liver pathologies. The adaptation was performed with the addition of androgen and estrogen receptor responses, the addition of connections between sex steroids and growth hormone, and the addition of gender-based growth hormone release $\left(\mathrm{see}^{20}\right)$. 
tween genders, we developed the LiverSex model ${ }^{20}$, the first gender-based, multi-tissue and multi-level liver metabolic computational model (see Figure 3). SteatoNet was reused and adapted to gender-based hormonal regulation of liver. The key step in the adaptation of liver metabolism to gender was the addition of androgen and estrogen receptor responses to relevant hormones, the additions of connections between sex steroids and growth hormone, and the addition of specific gender-based growth hormone release to the model. Hormonal regulation in LiverSex was simplified to a level that still ensures normal function. Hormones were organized into 3 groups: androgen, estrogens and growth hormone. Androgen and estrogen groups represent steroid hormones that regulate the development and maintenance of sex characteristics in mammals by binding to their corresponding receptors. ${ }^{92}$ The growth hormone has a daily oscillatory behaviour in males and has a constant concentration in females, which was also included in the model..$^{95}$ The dynamics of estrogen in the female model was described with the monthly estrous cycle that cannot be found in males. ${ }^{96}$ With these alterations, LiverSex was able to provide detailed insights into gender dependent complex liver pathologies in the liver-related disease development and progression. The model identified the cardinal gender dependent metabolic pathways such as partition of fatty acids to ketone body production, VLDL synthesis, and fatty acids oxidation, together with deposition of triglycerides as lipid droplets, which are involved in accumulation of triglyceride as one of the initial steps of NAFLD. Later was recognized as substantially more sensitive in females in response to a high-fat diet challenge. The ability to partition fatty acids into different pathways might be one of the possible protective mechanisms in females leading to delayed NAFLD progression compared to males. In the same way, PGC1A, PPARa, FXR and LXR were identified as regulatory factors, which could become influential in gender dependent personalized treatment of NAFLD.

\section{Future Perspectives}

In systems medicine, computational models can be applied for diagnostics, for prediction of disease progression, and for optimal selection of suitable therapeutic strategies. They give us the opportunity to personalise the clinical care to the patients' anatomy, physiology, genomic background, etc. In addition, systems medicine approaches highlight patient specific aspects on the development and progression of the diseases.

The liver has a major physiological role in the fine-tuning of metabolic pathways, including functions associated with health and disease. A comprehensive characterization of liver maintenance and disruptions might be crucial in preventive medicine and in the design of safer and more efficient therapeutic approaches. Systems medi- cine may help with finding preventive approaches for diseases of hepatic metabolism.

Computational models complement experimental data and can be used for diagnostic purposes, for identification of drug targets and for personalized care of patients with liver diseases. There is an urgent need for new therapies in hepatology, as the mortality and morbidity in many liver diseases is still high. End-stage liver diseases and cancers share a similar dismal prognosis.

The aim of personalised medicine is to adapt the diagnosis and clinical care to each individual patient. With the reduction of the probability of wrong diagnoses as well as the application of wrong therapies, personalized medicine has all the potentials to drastically reduce the costs of health care as well as global health risks. Personalized medicine, however, still needs an approval from the general audience of physicians as well as from the wider population. Making big data work for patients is still a challenge from the decision making to the data management as well as ethical and legal perspective. ${ }^{97}$ The consent policies need to be clear. The data and its interpretations need to be integrated into a comprehensive health care system that would have practical benefits for all participants, i.e. patients, clinicians and researchers. Other challenges that limit the bridging of personalized medicine to market include is current costs of multiomics experimental approaches and lack as well as inconsistencies of internationally accepted best practice standards. ${ }^{98}$

The majority of current personalized medicine approaches is directed towards the diagnosis and treatment of cancer. In comparison to the recent progress of personalized medicine in oncology, personalized medicine in hepatology still remains in its infancy. Several liver diseases, such as progression of NAFLD to HCC via NASH, are still hard to characterize in the context of their predictive outcome. We still do not fully understand the sex-dependent mechanisms that lead the development and progression of liver related diseases and which might be crucial for their diagnosis and treatment. We speculate these mechanisms are driven by growth hormone as well as sex hormones and their influences on gene expression patterns. In the future, broad molecular profiling of liver diseases, their integration in computational models and their validation in clinical trials, in females and males could improve the current treatment options with individualized care. These computational models will not only progress in their accuracy and prediction power of describing the dynamics of the metabolism of isolated organs or reactions networks. Current trends of systems biology in hepatology go towards the integration of different network types with multilayered omics data to obtain integrative models, which will accurately simulate whole-body metabolic functions. ${ }^{99}$

Scientific society has entered a new era in which computational methods and technologies have a key role in investigation of the human body. EuroPhysiome $e^{100-102}$ 
is an European project, which created a framework for modelling the human body using computational methods which incorporate the biochemistry, biophysics, and anatomy of cells, tissues and organs known as Homo sapiens in silico. These methods aim to design a computational version of the human body within the next 20 years. ${ }^{103}$ This will provide the comprehensive insights into the dynamics of the human body and development and progression of complex diseases, and increase their treatment potentials in the context of preventive and personalized medicine.

In conclusion, despite spectacular advances in the post-genome era, there is a gap between experimental data and medical knowledge, and an even greater gap between new knowledge in terms of clinical utility and benefits to the patients. We still suffer from multifactorial disorders that affect large-scale populations and we are unable to guide the epidemics due to the knowledge gaps. Progressive liver diseases arising from metabolic causes are a typical example where the classical approaches have not lead to sufficient progress. It is thus timely to introduce multi-disciplinary approaches and tackle NAFLD by combining biochemical experimentation with the state-of-the-art modelling. There are no approved therapies for NAFLD and the compounds currently in Phase III clinical trials may very likely face safety and efficacy issues. Further research and more individualized disease progression monitoring is also affected by a current lack of reliable non-invasive biomarkers. It is thus evident that in addition to experimental and clinical work we also need models to help us decrease the burden of liver pathologies.

\section{Acknowledgments}

Supported by the resources of FP7 CASyM (Coordinating Action Systems Medicine Europe, grant no. 305033), by Slovenian Research Agency grants P1-0390, P2-0359, and by the infrastructure grant ELIXIR.

\section{Author biographies}

Tanja Cvitanović Tomaš is a PhD student at the Faculty of Medicine, University of Ljubljana, Slovenia. She received her MSc from the Biotechnical Faculty, University of Ljubljana, Slovenia in 2012. Her research work is focused on interdisciplinary bridging between medicine, biochemistry and computational modelling. Her recent work is directed towards the applications of computational approaches to gain the insights into hot topics in hepatology.

Miha Moškon received his $\mathrm{BSc}$ and $\mathrm{PhD}$ degree in computer science from the Faculty of Computer and Information Science, University of Ljubljana, Slovenia in 2007 and 2012, where he holds the position of an assistant professor. His research work is focused on computational approaches in systems medicine, systems biology and synthetic biology. His main research interests have been re- cently directed towards accurate quantitative modelling and analysis of metabolic and gene regulatory networks and towards the computational design of synthetic biological systems.

Miha Mraz received his BSc, MSc and PhD degree in computer science from the Faculty of Computer and Information Science, University of Ljubljana, Slovenia in 1992, 1995 and 2000, where he leads the Computational biology group, and holds the position of a full professor. His research interests include unconventional processing methods and applications of computational approaches to systems biology, systems medicine and synthetic biology.

Damjana Rozman received her BSc at Faculty of Chemistry and Chemical Technology, University of Ljubljana, MSc and PhD degree at Faculty of Medicine, University of Ljubljana and post-doctoral training at Vanderbilt University in USA. She holds the position of full professor at Institute of Biochemistry and is the head of the Centre for Functional Genomics and Bio-chips at Faculty of Medicine. In her research she applies functional genomics and systems medicine approaches to decipher how the cholesterol homeostasis cross-talks with other liver metabolic pathways and how this influences liver health and transformation to disease.

\section{References}

1. Younossi, Z.; Henry, L. Contribution of Alcoholic and Nonalcoholic Fatty Liver Disease to the Burden of Liver-Related Morbidity and Mortality. Gastroenterology 2016, 150, 17781785. DOI:10.1053/j.gastro.2016.03.005

2. Naik, A.; Košir, R.; Rozman, D. Genomic Aspects of NAFLD Pathogenesis. Genomics 2013, 102, 84-95.

DOI:10.1016/j.ygeno.2013.03.007

3. Blagotinšek, K.; Rozman, D. Targeting Signalling Pathways in Hepatocellular Carcinoma. Curr. Pharm. Des. 2017, 23, 170175.

4. Ačimovič, J.; Rozman, D. Steroidal Triterpenes of Cholesterol Synthesis. Molecules 2013, 18, 4002-4017.

DOI: $10.3390 /$ molecules 18044002

5. Seliskar, M.; Rozman, D. Mammalian Cytochromes P450 -Importance of Tissue Specificity. Biochim Biophys Acta 2007, $1770,458-466$.

6. Fink, M.; Acimovic, J.; Rezen, T.; Tansek, N.; Rozman, D. Cholesterogenic Lanosterol 14alpha-Demethylase (CYP51) Is an Immediate Early Response Gene. Endocrinology 2005, 146, 5321-5331. DOI:10.1210/en.2005-0781

7. Kosir, R.; Prosenc Zmrzljak, U.; Korencic, A.; Juvan, P.; Acimovic, J.; Rozman, D. Mouse Genotypes Drive the Liver and Adrenal Gland Clocks. Sci. Rep. 2016, 6, 31955.

DOI:10.1038/srep31955

8. Lorbek, G.; Perše, M.; Jeruc, J.; Juvan, P.; Gutierrez-Mariscal, F. M.; Lewinska, M.; Gebhardt, R.; Horvat, S.; Björkhem, I.; 
Rozman, D. Lessons from Hepatocyte-Specific Cyp51 Knockout Mice: Impaired Cholesterol Synthesis Leads to Oval Cell-Driven Liver Injury. Sci. Rep. 2015, 5, 8777.

DOI:10.1038/srep08777

9. Keber, R.; Motaln, H.; Wagner, K. D.; Debeljak, N.; Rassoulzadegan, M.; Ačimovič, J.; Rozman, D.; Horvat, S. Mouse Knockout of the Cholesterogenic Cytochrome P450 Lanosterol 14a-Demethylase (Cyp51) Resembles Antley-Bixler Syndrome. J. Biol. Chem. 2011, 286, 29086-29097.

DOI:10.1074/jbc.M111.253245

10. Urlep, Ž.; Lorbek, G.; Perše, M.; Jeruc, J.; Juvan, P.; Matz-Soja, M.; Gebhardt, R.; Björkhem, I.; Hall, J. A.; Bonneau, R. Disrupting Hepatocyte Cyp51 from Cholesterol Synthesis Leads to Progressive Liver Injury in the Developing Mouse and Decreases RORC Signalling. Sci. Rep. 2017, 7, 40775.

DOI:10.1038/srep40775

11. Kovač, U.; Rozman, D. Genetics of Non-alcoholic Fatty Liver Disease. In eLS; John Wiley \& Sons, Ltd, 2015.

12. Skubic, C.; Drakulić, Ž.; Rozman, D. Pharmacogenetic Considerations for Personalized Therapy When Tackling Nonalcoholic Fatty Liver Disease: The Perspective of Genes, Drugs, and the Sex. Submitted 2018.

13. Cvitanović, T.; Reichert, M. C.; Moškon, M.; Mraz, M.; Lammert, F.; Rozman, D. Large-Scale Computational Models of Liver Metabolism: How Far from the Clinics? Hepatology 2017, 66, 1323-1334. DOI:10.1002/hep.29268

14. Duffy, D. J. Problems, Challenges and Promises: Perspectives on Precision Medicine. Brief. Bioinform. 2016, 17, 494-504. DOI:10.1093/bib/bbv060

15. Wolkenhauer, O. Why Model? Front. Physiol. 2014, 5, 21. DOI:10.3389/fphys.2014.00021

16. Mengel, B.; Hunziker, A.; Pedersen, L.; Trusina, A.; Jensen, M. H.; Krishna, S. Modeling Oscillatory Control in NF-KB, P53 and Wnt Signaling. Curr. Opin. Genet. Dev. 2010, 20, 656-664. DOI:10.1016/j.gde.2010.08.008

17. Brunk, E.; Sahoo, S.; Zielinski, D. C.; Altunkaya, A.; Dräger, A.; Mih, N.; Gatto, F; Nilsson, A.; Preciat Gonzalez, G. A.; Aurich, M. K.; et al. Recon3D Enables a Three-Dimensional View of Gene Variation in Human Metabolism. Nat. Biotechnol. 2018, 36, 272-281. DOI:10.1038/nbt.4072

18. Karr, J. R.; Sanghvi, J. C.; MacKlin, D. N.; Gutschow, M. V.; Jacobs, J. M.; Bolival, B.; Assad-Garcia, N.; Glass, J. I.; Covert, M. W. A Whole-Cell Computational Model Predicts Phenotype from Genotype. Cell 2012, 150, 389-401.

DOI:10.1016/j.cell.2012.05.044

19. Hoehme, S.; Friebel, A.; Hammad, S.; Drasdo, D.; Hengstler, J. G. Creation of Three-Dimensional Liver Tissue Models from Experimental Images for Systems Medicine. Methods Mol. Biol. 2017, 1506, 319-362.

DOI:10.1007/978-1-4939-6506-9_22

20. Cvitanović Tomaš, T.; Urlep, Ž.; Moškon, M.; Mraz, M.; Rozman, D. LiverSex Computational Model: Sexual Aspects in Hepatic Metabolism and Abnormalities. Front. Physiol. 2018, 9, 360. DOI:10.3389/fphys.2018.00360

21. Ingalls, B. P. Mathematical Modelling in Systems Biology: An Introduction; MIT Press, 2014.
22. Kærn, M.; Blake, W. J.; Collins, J. J. The Engineering of Gene Regulatory Networks. Annu. Rev. Biomed. Eng. 2003, 5, 179206. DOI:10.1146/annurev.bioeng.5.040202.121553

23. Turner, T. E.; Schnell, S.; Burrage, K. Stochastic Approaches for Modelling in Vivo Reactions. Comput. Biol. Chem. 2004, 28, 165-178. DOI:10.1016/j.compbiolchem.2004.05.001

24. Gillespie, D. T. Deterministic Limit of Stochastical Chemical Kinetics. J. Phys. Chem. B 2009, 113, 1640-1644.

DOI:10.1021/jp806431b

25. Karlebach, G.; Shamir, R. Modelling and Analysis of Gene Regulatory Networks. Nat. Rev. Mol. Cell Biol. 2008, 9, 770780. DOI: $10.1038 / \mathrm{nrm} 2503$

26. De Jong, H. Modeling and Simulation of Genetic Regulatory Systems: A Literature Review. J. Comput. Biol. 2002, 9, 67103. DOI: $10.1089 / 10665270252833208$

27. Gillespie, D. T. Exact Stochastic Simulation of Coupled Chemical Reactions. J. Phys. Chem. 1977, 81, 2340-2361. DOI:10.1021/j100540a008

28. Petroni, M.; Zimic, N.; Mraz, M.; Moškon, M. Stochastic Simulation Algorithm for Gene Regulatory Networks with Multiple Binding Sites. J. Comput. Biol. 2015, 22, 218-226. DOI:10.1089/cmb.2014.0064

29. Babtie, A. C.; Stumpf, M. P. H. How to Deal with Parameters for Whole-Cell Modelling. J. R. Soc. Interface 2017, 14, 20170237. DOI:10.1098/rsif.2017.0237

30. Ashyraliyev, M.; Fomekong-Nanfack, Y.; Kaandorp, J. A.; Blom, J. G. Systems Biology: Parameter Estimation for Biochemical Models. FEBS J. 2009, 276, 886-902.

DOI:10.1111/j.1742-4658.2008.06844.x

31. Gábor, A.; Banga, J. R. Robust and Efficient Parameter Estimation in Dynamic Models of Biological Systems. BMC Syst. Biol. 2015, 9, 74. DOI:10.1186/s12918-015-0219-2

32. Zhan, C.; Yeung, L. F. Parameter Estimation in Systems Biology Models Using Spline Approximation. BMC Syst. Biol. 2011, 5, 14. DOI:10.1186/1752-0509-5-14

33. Sun, J.; Garibaldi, J. M.; Hodgman, C. Parameter Estimation Using Metaheuristics in Systems Biology: A Comprehensive Review. IEEE/ACM Trans. Comput. Biol. Bioinforma. 2012, 9, 185-202.

34. Lillacci, G.; Khammash, M. Parameter Estimation and Model Selection in Computational Biology. PLoS Comput. Biol. 2010, 6, e1000696. DOI:10.1371/journal.pcbi.1000696

35. Penas, D. R.; González, P.; Egea, J. A.; Doallo, R.; Banga, J. R. Parameter Estimation in Large-Scale Systems Biology Models: A Parallel and Self-Adaptive Cooperative Strategy. BMC Bioinformatics 2017, 18, 1-24.

DOI:10.1186/s12859-016-1452-4

36. Rozman, D. From Nonalcoholic Fatty Liver Disease to Hepatocellular Carcinoma: A Systems Understanding. Dig. Dis. Sci. 2014, 59, 238-241. DOI:10.1007/s10620-013-2998-x

37. Saadatpour, A.; Réka, A. Boolean Modeling of Biological Regulatory Networks: A Methodology Tutorial. Methods 2013, 62, 3-12. DOI:10.1016/j.ymeth.2012.10.012

38. O’Brien, E. J.; Monk, J. M.; Palsson, B. O. Using Genome-Scale Models to Predict Biological Capabilities. Cell 2015, 161, 971-987. DOI:10.1016/j.cell.2015.05.019 
39. Wynn, M. L.; Consul, N.; Merajver, S. D.; Schnell, S. Logic-Based Models in Systems Biology: A Predictive and Parameter-Free Network Analysis Method. Integr. Biol. 2012, 4, 1323. DOI:10.1039/c2ib20193c

40. Le Novere, N. Quantitative and Logic Modelling of Molecular and Gene Networks. Nat. Rev. Genet. 2015, 16, 146-158. DOI:10.1038/nrg3885

41. Ivanov, I. Boolean Models of Genomic Regulatory Networks: Reduction Mappings, Inference, and External Control. Curr. Genomics 2009, 10, 375-387. DOI:10.2174/138920209789177584

42. Martin, S.; Zhang, Z.; Martino, A.; Faulon, J. L. Boolean Dynamics of Genetic Regulatory Networks Inferred from Microarray Time Series Data. Bioinformatics 2007, 23, 866-874. DOI:10.1093/bioinformatics/btm021

43. Rejc, Ž.; Magdevska, L.; Tršelič, T.; Osolin, T.; Vodopivec, R.; Mraz, J.; Pavliha, E.; Zimic, N.; Cvitanović, T.; Rozman, D.; et al. Computational Modelling of Genome-Scale Metabolic Networks and Its Application to CHO Cell Cultures. Comput. Biol. Med. 2017, 88, 150-160.

DOI:10.1016/j.compbiomed.2017.07.005

44. Orth, J. D.; Conrad, T. M.; Na, J.; Lerman, J. A.; Nam, H.; Feist, A. M.; Palsson, B. A Comprehensive Genome-Scale Reconstruction of Escherichia Coli Metabolism. Mol. Syst. Biol. 2011, 11, 535.

45. Sánchez, B. J.; Nielsen, J. Genome Scale Models of Yeast: Towards Standardized Evaluation and Consistent Omic Integration. Integr. Biol. 2015, 7, 846-858.

DOI:10.1039/C5IB00083A

46. Hefzi, H.; Ang, K. S.; Hanscho, M.; Bordbar, A.; Ruckerbauer, D.; Lakshmanan, M.; Orellana, C. A.; Baycin-Hizal, D.; Huang, Y.; Ley, D.; et al. A Consensus Genome-Scale Reconstruction of Chinese Hamster Ovary Cell Metabolism. Cell Syst. 2016, 3, 434-443.

DOI:10.1016/j.cels.2016.10.020

47. Wang, Y.; Eddy, J. A.; Price, N. D. Reconstruction of Genome-Scale Metabolic Models for 126 Human Tissues Using MCADRE. BMC Syst. Biol. 2012, 6, 153.

DOI:10.1186/1752-0509-6-153

48. Mardinoglu, A.; Agren, R.; Kampf, C.; Asplund, A.; Uhlen, M.; Nielsen, J. Genome-Scale Metabolic Modelling of Hepatocytes Reveals Serine Deficiency in Patients with Non-Alcoholic Fatty Liver Disease. Nat. Commun. 2014, 5, 1-11. DOI: $10.1038 /$ ncomms4083

49. Ghaffari, P.; Mardinoglu, A.; Nielsen, J. Cancer Metabolism: A Modeling Perspective. Front. Physiol. 2015, 6, 382.

DOI:10.3389/fphys.2015.00382

50. Agren, R.; Mardinoglu, A.; Asplund, A.; Kampf, C.; Uhlen, M.; Nielsen, J. Identification of Anticancer Drugs for Hepatocellular Carcinoma through Personalized Genome-Scale Metabolic Modeling. Mol. Syst. Biol. 2014, 10, 721.

DOI: $10.1002 / \mathrm{msb} .145122$

51. Becker, S. A.; Palsson, B. O. Context-Specific Metabolic Networks Are Consistent with Experiments. PLoS Comput. Biol. 2008, 4, e1000082.

DOI:10.1371/journal.pcbi.1000082
52. Schultz, A.; Qutub, A. A. Reconstruction of Tissue-Specific Metabolic Networks Using CORDA. PLoS Comput. Biol. 2016, 12, 1-33. DOI:10.1371/journal.pcbi.1004808

53. Orth, J. D.; Thiele, I.; Palsson, B. Ø. What Is Flux Balance Analysis? Nat. Biotechnol. 2010, 28, 245-248.

DOI:10.1038/nbt.1614

54. Heirendt, L.; Arreckx, S.; Pfau, T.; Mendoza, S. N.; Richelle, A.; Heinken, A.; Haraldsdóttir, H. S.; Wachowiak, J.; Keating, S. M.; Vlasov, V.; et al. Creation and Analysis of Biochemical Constraint-Based Models: The COBRA Toolbox v3.0. Dev. Biol. 2017, 276, 391-402.

55. Lee, S.; Zhang, C.; Kilicarslan, M.; Piening, B. D.; Bjornson, E.; Hallström, B. M.; Groen, A. K.; Ferrannini, E.; Laakso, M.; Snyder, M.; et al. Integrated Network Analysis Reveals an Association between Plasma Mannose Levels and Insulin Resistance. Cell Metab. 2016, 24, 172-184.

DOI:10.1016/j.cmet.2016.05.026

56. Lee, S.; Mardinoglu, A.; Zhang, C.; Lee, D.; Nielsen, J. Dysregulated Signaling Hubs of Liver Lipid Metabolism Reveal Hepatocellular Carcinoma Pathogenesis. Nucleic Acids Res. 2016, 44, 5529-5539. DOI:10.1093/nar/gkw462

57. Karr, J. R.; Takahashi, K.; Funahashi, A. The Principles of Whole-Cell Modeling. Curr. Opin. Microbiol. 2015, 27, 1824. DOI:10.1016/j.mib.2015.06.004

58. Widmer, L. A.; Stelling, J. Bridging Intracellular Scales by Mechanistic Computational Models. Curr. Opin. Biotechnol. 2018, 52, 17-24. DOI:10.1016/j.copbio.2018.02.005

59. Apri, M.; De Gee, M.; Van Mourik, S.; Molenaar, J. Identifying Optimal Models to Represent Biochemical Systems. PLoS One 2014, 9, e83664.

DOI:10.1371/journal.pone.0083664

60. Nikolaev, E. V.; Sontag, E. D. Quorum-Sensing Synchronization of Synthetic Toggle Switches: A Design Based on Monotone Dynamical Systems Theory. PLoS Comput. Biol. 2016, 12, e1004881. DOI:10.1371/journal.pcbi.1004881

61. Chen, Y.; Kim, J. K.; Hirning, A. J.; Josić, K.; Bennett, M. R. Emergent Genetic Oscillations in a Synthetic Microbial Consortium. Science 2015, 349, 986-989.

DOI:10.1126/science.aaa3794

62. Ricken, T.; Werner, D.; Holzhütter, H. G.; König, M.; Dahmen, U.; Dirsch, O. Modeling Function-perfusion Behavior in Liver Lobules Including Tissue, Blood, Glucose, Lactate and Glycogen by Use of a Coupled Two-Scale PDE-ODE Approach. Biomech. Model. Mechanobiol. 2015, 14, 515-536. DOI:10.1007/s10237-014-0619-z

63. Gorochowski, T. E. Agent-Based Modelling in Synthetic Biology. Essays Biochem. 2016, 60, 325-336.

DOI:10.1042/EBC20160037

64. Matyjaszkiewicz, A.; Fiore, G.; Annunziata, F.; Grierson, C. S.; Savery, N. J.; Marucci, L.; Di Bernardo, M. BSim 2.0: An Advanced Agent-Based Cell Simulator. ACS Synth. Biol. 2017, 6, 1969-1972. DOI:10.1021/acssynbio.7b00121

65. Swat M H, Thomas G L, Belmonte J M, Shirinifard A, Hmeljak D, G. J. A. Multi-Scale Modeling of Tissues Using CompuCell3D. Methods Cell Biol. 2012, 110, 325-366.

DOI:10.1016/B978-0-12-388403-9.00013-8 
66. Friebel, A.; Neitsch, J.; Johann, T.; Hammad, S.; Hengstler, J. G.; Drasdo, D.; Hoehme, S. TiQuant: Software for Tissue Analysis, Quantification and Surface Reconstruction. Bioinformatics 2015, 31, 3234-3236.

DOI:10.1093/bioinformatics/btv346

67. Dutta-Moscato, J.; Solovyev, A.; Mi, Q.; Nishikawa, T.; Soto-Gutierrez, A.; Fox, I. J.; Vodovotz, Y. A Multiscale AgentBased in Silico Model of Liver Fibrosis Progression. Front. Bioeng. Biotechnol. 2014, 2, 18.

DOI:10.3389/fbioe.2014.00018

68. Wolkenhauer, O.; Auffray, C.; Brass, O.; Clairambault, J.; Deutsch, A.; Drasdo, D.; Gervasio, F.; Preziosi, L.; Maini, P.; Marciniak-Czochra, A.; et al. Enabling Multiscale Modeling in Systems Medicine. Genome Med. 2014, 6, 4-6. DOI:10.1186/gm538

69. Belič, A.; Ačimovič, J.; Naik, A.; Goličnik, M. Analysis of the Steady-State Relations and Control-Algorithm Characterisation in a Mathematical Model of Cholesterol Biosynthesis. Simul. Model. Pract. Theory 2013, 33, 18-27.

DOI:10.1016/j.simpat.2011.12.010

70. Naik, A.; Rozman, D.; Belič, A. SteatoNet: The First Integrated Human Metabolic Model with Multi-Layered Regulation to Investigate Liver-Associated Pathologies. PLoS Comput Biol 2014, 10, e1003993. DOI:10.1371/journal.pcbi.1003993

71. Ayers, D.; Day, P. J. Systems Medicine: The Application of Systems Biology Approaches for Modern Medical Research and Drug Development. Mol. Biol. Int. 2015, 2015, 1-8.

72. Guilder, L.; Pula, S.; Pierre, G. Metabolic Disorders Presenting as Liver Disease. Paediatr. Child Heal. (United Kingdom) 2017, 27, 533-539. DOI:10.1016/j.paed.2017.07.007

73. Hafezi-Bakhtiari, S.; Adeyi, O. A. Metabolic Disorders of the Liver. Diagnostic Histopathol. 2014, 20, 125-133.

DOI:10.1016/j.mpdhp.2014.01.012

74. Gille, C.; Bölling, C.; Hoppe, A.; Bulik, S.; Hoffmann, S.; Hübner, K.; Karlstädt, A.; Ganeshan, R.; König, M.; Rother, K.; et al. HepatoNet1: A Comprehensive Metabolic Reconstruction of the Human Hepatocyte for the Analysis of Liver Physiology. Mol. Syst. Biol. 2010, 6, 411. DOI:10.1038/msb.2010.62

75. Björnson, E.; Mukhopadhyay, B.; Asplund, A.; Pristovsek, N.; Cinar, R.; Romeo, S.; Uhlen, M.; Kunos, G.; Nielsen, J.; Mardinoglu, A. Stratification of Hepatocellular Carcinoma Patients Based on Acetate Utilization. Cell Rep. 2015, 13, 2014-2026. DOI:10.1016/j.celrep.2015.10.045

76. Klover, P. J.; Mooney, R. A. Hepatocytes: Critical for Glucose Homeostasis. Int. J. Biochem. Cell Biol. 2004, 36, 753-758.

DOI:10.1016/j.biocel.2003.10.002

77. König, M.; Bulik, S.; Holzhütter, H.-G. Quantifying the Contribution of the Liver to Glucose Homeostasis: A Detailed Kinetic Model of Human Hepatic Glucose Metabolism. PLoS Comput. Biol. 2012, 8, e1002577.

DOI:10.1371/journal.pcbi.1002577

78. Ashworth, W. B.; Davies, N. A.; Bogle, I. D. L. A Computational Model of Hepatic Energy Metabolism: Understanding Zonated Damage and Steatosis in NAFLD. PLoS Comput. Biol. 2016, 12, e1005105.

DOI:10.1371/journal.pcbi.1005105
79. Schleicher, J.; Dahmen, U.; Guthke, R.; Schuster, S. Zonation of Hepatic Fat Accumulation: Insights from Mathematical Modelling of Nutrient Gradients and Fatty Acid Uptake. J. $R$. Soc. Interface 2017, 14, 20170443.

DOI:10.1098/rsif.2017.0443

80. Mitchell, S.; Mendes, P. A Computational Model of Liver Iron Metabolism. PLoS Comput. Biol. 2013, 9, e1003299.

DOI:10.1371/journal.pcbi.1003299

81. Sluka, J. P.; Fu, X.; Swat, M.; Belmonte, J. M.; Cosmanescu, A.; Clendenon, S. G.; Wambaugh, J. F.; Glazier, J. A. A Liver-Centric Multiscale Modeling Framework for Xenobiotics. PLoS One 2016, 11, e0162428. DOI:10.1371/journal.pone.0162428

82. Drasdo, D.; Hoehme, S.; Hengstler, J. G. How Predictive Quantitative Modelling of Tissue Organization Can Inform Liver Disease Pathogenesis. J. Hepatol. 2014, 61, 951-956. DOI:10.1016/j.jhep.2014.06.013

83. Naito, Y. A Computational Model of the Hepatic Lobule. In E-Cell System; Springer: New York, 2013; pp 143-155.

DOI:10.1007/978-1-4614-6157-9_9

84. Hoehme, S.; Brulport, M.; Bauer, A.; Bedawy, E.; Schormann, W.; Hermes, M.; Puppe, V.; Gebhardt, R.; Zellmer, S.; Schwarz, M.; et al. Prediction and Validation of Cell Alignment along Microvessels as Order Principle to Restore Tissue Architecture in Liver Regeneration. Proc. Natl. Acad. Sci. 2010, 107, 10371-10376. DOI:10.1073/pnas.0909374107

85. Chan, S. L.; Wong, A. M.; Lee, K.; Wong, N.; Chan, A. K. C. Personalized Therapy for Hepatocellular Carcinoma: Where Are We Now? Cancer Treat. Rev. 2016, 45, 77-86.

DOI:10.1016/j.ctrv.2016.02.008

86. Yang, J. D.; Roberts, L. R. Hepatocellular Carcinoma: A Global View. Nat. Rev. Gastroenterol. Hepatol. 2010, 7, 448-458. DOI:10.1038/nrgastro.2010.100

87. Folger, O.; Jerby, L.; Frezza, C.; Gottlieb, E.; Ruppin, E.; Shlomi, T. Predicting Selective Drug Targets in Cancer through Metabolic Networks. Mol. Syst. Biol. 2011, 7, 501.

DOI:10.1038/msb.2011.35

88. Duarte, N. C.; Becker, S. A.; Jamshidi, N.; Thiele, I.; Mo, M. L.; Vo, T. D.; Srivas, R.; Palsson, B. O. Global Reconstruction of the Human Metabolic Network Based on Genomic and Bibliomic Data. Proc. Natl. Acad. Sci. 2007, 104, 1777-1782. DOI:10.1073/pnas.0610772104

89. Jerby, L.; Shlomi, T.; Ruppin, E. Computational Reconstruction of Tissue-Specific Metabolic Models: Application to $\mathrm{Hu}$ man Liver Metabolism. Mol. Syst. Biol. 2010, 6, 401.

DOI:10.1038/msb.2010.56

90. Bordbar, A.; Feist, A. M.; Usaite-Black, R.; Woodcock, J.; Palsson, B. O.; Famili, I. A Multi-Tissue Type Genome-Scale Metabolic Network for Analysis of Whole-Body Systems Physiology. BMC Syst. Biol. 2011, 5, 180.

DOI:10.1186/1752-0509-5-180

91. Agren, R.; Bordel, S.; Mardinoglu, A.; Pornputtapong, N.; Nookaew, I.; Nielsen, J. Reconstruction of Genome-Scale Active Metabolic Networks for 69 Human Cell Types and 16 Cancer Types Using INIT. PLoS Comput. Biol. 2012, 8, e1002518.

DOI:10.1371/journal.pcbi.1002518 
92. Roy, A. K.; Chatterjee, B. Sexual Dimorphism in the Liver. Annu. Rev. Physiol. 1983, 45, 37-50.

DOI:10.1146/annurev.ph.45.030183.000345

93. Durazzo, M.; Belci, P.; Collo, A.; Prandi, V.; Pistone, E.; Martorana, M.; Gambino, R.; Bo, S. Gender Specific Medicine in Liver Diseases: A Point of View. World J. Gastroenterol. 2014, 20, 2127-2135. DOI:10.3748/wjg.v20.i9.2127

94. Zhang, Y.; Laz, E. V; Waxman, D. J. Dynamic, Sex-Differential STAT5 and BCL6 Binding to Sex-Biased, Growth Hormone-Regulated Genes in Adult Mouse Liver. Mol Cell Biol 2012, 32, 880-896. DOI:10.1128/MCB.06312-11

95. Waxman, D. J.; O'connor, C. Growth Hormone Regulation of Sex-Dependent Liver Gene Expression. Mol. Endocrinol. 2006, 20, 2613-2629. DOI:10.1210/me.2006-0007

96. Gui, Y.; Silha, J. V.; Murphy, L. J. Sexual Dimorphism and Regulation of Resistin, Adiponectin, and Leptin Expression in the Mouse. Obes. Res. 2004, 12, 1481-1491.

DOI:10.1038/oby.2004.185

97. Cordeiro, J. V. Ethical and Legal Challenges of Personalized Medicine: Paradigmatic Examples of Research, Prevention, Diagnosis and Treatment. Rev. Port. Saúde Pública 2014, 32, 164-180. DOI:10.1016/j.rpsp.2014.10.002

98. Knowles, L.; Luth, W.; Bubela, T. Paving the Road to Personalized Medicine: Recommendations on Regulatory, Intellectual Property and Reimbursement Challenges. J. Law Biosci. 2017, 4, 453-506. DOI:10.1093/jlb/lsx030
99. Mardinoglu, A.; Boren, J.; Smith, U.; Uhlen, M.; Nielsen, J. Systems Biology in Hepatology: Approaches and Applications. Nat. Rev. Gastroenterol. Hepatol. 2018, 15, 365-377. DOI:10.1038/s41575-018-0007-8

100. Fenner, J. W.; Brook, B.; Clapworthy, G.; Coveney, P. V.; Feipel, V.; Gregersen, H.; Hose, D. R.; Kohl, P.; Lawford, P.; McCormack, K. M.; et al. The EuroPhysiome, STEP and a Roadmap for the Virtual Physiological Human. Philos. Trans. R. Soc. A Math. Phys. Eng. Sci. 2008, 366, 2979-2999. DOI:10.1098/rsta.2008.0089

101. Hunter, P.; Coveney, P. V.; de Bono, B.; Diaz, V.; Fenner, J.; Frangi, A. F.; Harris, P.; Hose, R.; Kohl, P.; Lawford, P.; et al. A Vision and Strategy for the Virtual Physiological Human in 2010 and Beyond. Philos. Trans. R. Soc. A Math. Phys. Eng. Sci. 2010, 368, 2595-2614.

DOI:10.1098/rsta.2010.0048

102. Hunter, P.; Chapman, T.; Coveney, P. V; De Bono, B.; Diaz, V.; Fenner, J.; Frangi, A. F.; Harris, P.; Hose, R.; Kohl, P.; et al. A Vision and Strategy for the Virtual Physiological Human: 2012 Update. Interface Focus 2013, 3, 20130004. DOI:10.1098/rsfs.2013.0004

103. Kolodkin, A.; Boogerd, F. C.; Plant, N.; Bruggeman, F. J.; Goncharuk, V.; Lunshof, J.; Moreno-Sanchez, R.; Yilmaz, N.; Bakker, B. M.; Snoep, J. L.; et al. Emergence of the Silicon Human and Network Targeting Drugs. Eur. J. Pharm. Sci. 2012, 46, 190-197. DOI:10.1016/j.ejps.2011.06.006

\section{Povzetek}

Računski modeli presnove jeter postajajo vse bolj pomembni in prepoznavni v raziskavah na področju sistemske medicine. $\mathrm{V}$ zadnjih letih so se pojavile tudi njihove prve klinične aplikacije v kontekstu personalizirane medicine. $\mathrm{V}$ pričujočem prispevku predstavimo pregled eksperimentalnih in računskih modelov, ki jih lahko uporabimo pri opisovanju in razumevanju presnovnih procesov in silico. Pregledamo zadnje trende pri razvoju obsežnih računskih modelov presnove jeter, kjer se osredotočimo na objektno-orientirane pristope modeliranja, ki predstavljajo eno od glavnih usmeritev naših raziskav. Prednosti objektno-orientiranih pristopov so v relativno enostavnem opisovanju interakcij med tkivi, kot je npr. interakcija presnove jeter $\mathrm{z}$ okoliškimi tkivi preko krvi. $\mathrm{V}$ nasprotju $\mathrm{z}$ alternativnimi pristopi modeliranja objektno-oritentirani pristopi omogočajo neposredno vključitev tako transkripcijske kot tudi posttranslacijske regulacije presnovnih reakcij. Na koncu prispevka opredelimo obstoječe in potencialne klinične aplikacije obsežnih računskih modelov presnove jeter ter opredelimo potenciale tako modelov presnovne kot tudi modelov ostalih celičnih procesov na področju sistemske in translacijske medicine. 